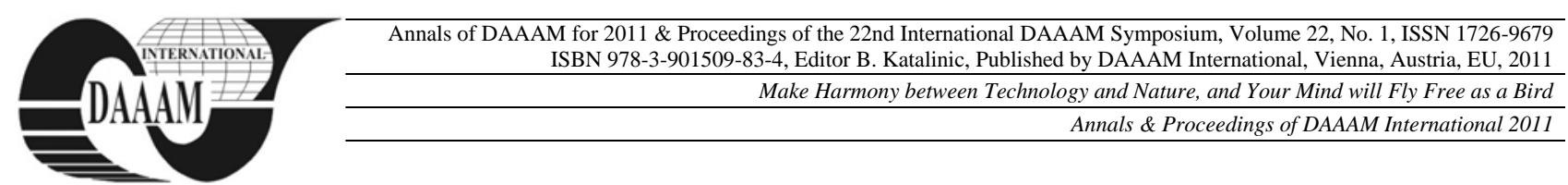

\title{
SUSTAINABLE DEVELOPMENT IN SMALL AND MEDIUM-SIZED ENGINEERING COMPANIES
}

\author{
ANDRASOVA, A[ndrea]; HAJNIK, B[artolomej] \& ZLOCHA, J[ozef]
}

\begin{abstract}
A n}$ article is based on an analysis of the development of skills of workers which had been done in several small and medium-sized engineering companies. The analysis had been performed in 2010 in the initial research related to another direction of $\mathrm{PhD}$ thesis. The article presents data collected in controlled interviews with managers responsible for human resources. The obtained information was used to increase the knowledge in the area human resources and sustainable development in this sector.
\end{abstract}

Key words: sustainable development, human resources, motivation, engineering companies

\section{INTRODUCTION}

A need to ensure sustainable development is one of the current global challenges of our time. Small and medium-sized engineering companies are now more than ever forced to reduce costs. This can have a positive effect on the efficient usage of resources, but also brings risks for the environment and security stakeholders. In this situation, the management skills of leadership and responsibility must be fully used and an awareness of all company personnel has to be at a high level. In order to ensure business economic, environmental and social development it is essential to dispose by properly educated and motivated workers.

\section{ANALYSIS OF POSSIBILITIES FOR WORKERS DEVELOPMENT}

Companies having an interest in developing and supporting its employees beyond the legal obligations have been using various instruments and methods of improving (CSR, EFQM, HCS-3E, etc.). Those companies that take care about their employees (the development of their knowledge, skills and abilities), are also affecting the surrounding companies and society at all. Mentioned methods and tools enable businesses to ensure sustainable economic growth and to decrease significant suffering of the environment, employees or the company. Despite of the undeniable advantages of these methods, they are often overlooked. All these tools are grounded in the fundamentals of ethical principles, which seek to promote in the world aimed at profit. As Mr. Sedlacek stated: not so long ago when ethics was considered a luxury icing on the cake of profitability and wealth. Today it starts to be the generally recognized that the economy is doing better in the ethical environment where players obey rules of the game. (Sedlacek, 2009)

\subsection{Human resources in sustainable development}

Sustainable development means a targeted, long-term (continuous) comprehensive and synergetic process, and conditions affecting all aspects of life (cultural, social, economic, environmental and institutional) at all levels (local, regional, global) and oriented to such a model of a community (local and regional communities, countries, international community), which meets the biological, physical, spiritual and social needs and interests of people, while eliminating or significantly reducing interventions threatening, damaging or destroying the conditions and forms of life, does not pollute the landscape over the bearing peace, uses its resources wisely and protecting cultural and natural heritage. $(* * *, 2011)$

Sustainable development consists of three main pillars, namely:

- The social pillar,

- The economic pillar,

- The environmental pillar.

This distribution can only be regarded as formal as the coherence of individual areas, whether social, environmental or economic is so strong that it is hard to set boundaries between them. All these pillars connect people and their needs. Satisfying of needs is for people in the first place. It should not be shortsighted and the care must be taken in the long term sustainability. People in leading firms in the market must not forget the responsibility to employees, to customers, to the surroundings, environment and society so that the sustainable development is ensured. Only by changing of the values and reviewing of priorities of a person and all human society can ensured the sustainable development. The company can not rely only on changes in technologies and new technical solutions, people's behavior should be changed as well.

\subsection{CSR, EFQM - different ways of sustainable development \\ CSR - (Corporate Social Responsibility) brings a new} perspective on the societal role of business awareness of the link between profitability and environmental standards of ethical business. Companies are focusing increasingly on environmental protection, local community development, ethical business, improving relationships with employees and partners. Corporate social responsibility can be considered a source of competitive advantage and innovation to help businesses remain on the market. (Sakal, P. et al., 2009)

EFQM - (European Foundation for Quality Management) Excellence Model is used for the evaluation of "excellence" of the organization. This assessment is carried out by using of the method of assessment type RADAR. EFQM gives the organization the opportunity to assess how "good" it is to the model and its results can be compared with other model by using benchmarking.

Evaluation by the EFQM excellence model.

The main advantage of using the EFQM excellence model is its flexibility and applicability in all organizations, regardless of:

- Country,

- Size,

- Sector,

- Structure,

- Level of excellence 
and also may be applicated to the service sector (offices, hospitals, schools). (Paulova, I.; Hekelova, E. \& Satan, A. \& Salgovicova, J., 2008).

\subsection{HCS model 3E of participating ergonomics}

HCS model 3E was created based on the results and lessons learned during four years of running the project "Participatory Ergonomics".

This model sees a man as an object as well as a subject of all efforts. We focus here on the concept in which working conditions are contributing in improving of the quality of life of every employee in sustainable and acceptable conditions of environmental quality and efficient economic conditions. (Hatiar, Cook, Sakal, 2006)

\subsection{Results of analysis of personnel development opportunities}

This chapter provides the results of the analysis of options for development of skills of employees in several small and medium-sized engineering companies. The analysis had been performed in 2010 in the initial research related to another direction of $\mathrm{PhD}$ thesis. A number of surveyed firms was 20 which was sufficient enough to fulfill the target of the objective analysis. The article presents data collected in controlled interviews with managers responsible for human resources. The obtained information was used to have a better knowledge in the area of human resources and sustainable development in this sector. Considering a form of a report and in order to achieve a bigger transparency has been rejected a graphical representation.

\subsection{Developing of skills of workers in OSH and environmental area}

All organizations which participated in research have been training their staff in $\mathrm{OSH}$ and the environment area in regular intervals.

Irregular additional training has been performed at $20 \%$ of organizations. An encouragement in participation in conferences declares $10 \%$ of companies and $20 \%$ of them support the participation in exhibitions with the theme of health and safety guidelines. New materials concerning this topic provides $55 \%$ of researched organizations.

\subsection{Support and motivation in engagement to improvement of the environment}

The support and the motivation in engagement to improvement of the environment declared $60 \%$ of organizations and in all cases it was a financial motivation.

\subsection{Sharing of the knowledge between the organization and the staff}

All participating organizations have assured an exchange of the knowledge. This has been mainly done in regular meetings and surveys among workers.

\subsection{Evaluation to maintain competence of employees in the environmental, health and safety area}

Regular evaluation of the competence of employees in OSH performs $60 \%$ of organizations and $10 \%$ of them performs irregular evaluation. No evaluation in this theme does $20 \%$ of organizations. Periodic evaluation of competence in the area of environment declares $30 \%$ of companies and $10 \%$ performs occasional evaluation of the competence in the area of environment.

\subsection{Methods of training of employees}

The education by lessons and seminars takes place in $70 \%$ of the organizations. Self-education is supported by $60 \%$ of organizations. Rotation in the work positions as a learning method uses $20 \%$ of organizations. Internet training for workers has been used in $60 \%$ of organizations.

The findings show that the studied organizations take different approaches to the development of skills and knowledge of their workers.

At the time of research organizations had been struggling with an economic recession, which significantly affected the engineering sector. All representatives of organizations confirmed education as a priority, but they are more than ever trying to find alternative (cheaper) options. However, there was often described a problem of a willingness of employees to learn, especially in the area of educational activities aimed to a sustainable development the employees do not see a sense.

Research had been conducted in the region with a long tradition in engineering production, which had been after 1989 in a decline and is now gaining prominence. The transition to a private enterprise has brought a strong focus on "quick" profits which disagrees with the concept of sustainable development. However, in managements of the surveyed companies are managers who understand that the concept of sustainable development or CSR is important.

Used methods:

- $\quad$ system analysis and synthesis

- method of induction and deduction

- comparison and abstraction

\section{ACKNOWLEDGEMENTS}

This paper was supported by the Slovak Research and Development Agency under the contract No. LPP-0384-09: "Concept HCS model 3E vs. Concept Corporate Social Responsibility (CSR)."

\section{CONCLUSION}

The research results showed such deficiencies in industrial companies in the area of sustainable development. The analysis revealed the great possibility of improvement in incentives. It turned out the way my future work. So my $\mathrm{PhD}$ thesis development will lead to a motivation for a provision of sustainable development in industrial companies. Specifically, further research will be directed to the creation of the system of motivation to TUR.

The sustainability must become the very basis of the life, which joins an already clear concept such as profit and loss, debt and the value of the shares and capital costs, which will cause that our system will work. (Stead, Stead, 1998)

\section{REFERENCES}

Hatiar, K. \& Cook, T. M. \& Sakal, P. "HCS 3E" model of participatory ergonomics (2006) Availablefrom: http://www.mtf.stuba.sk/docs//internetovy_casopis/2006/3/ hatiar.pdf. Accessed: 2010-9-25

Paulova, I.; Hekelova, E. \& Satanova, A. \& Salgovicova, J. (2008) Methods of improving efficiency and effectiveness of TQM, STU, ISBN 978-80-227-2857-7, Bratislava

Sakal, P. a kol. (2009). Logistics company executive. SP SYNERGIA, 978-80-254-5754-2, Trnava

Sedlacek, T. (2009). Economics of Good and Evil,65.pole, 97880903944-3-8, Praha

Stead, W.E. \& Stead J.G.(1998) Management for a small planet. G plus G, 80-86103 15-3, Praha

*** (2001). The National Strategy of Sustainable Development. Available from:http://www.tur.vlada.gov.sk/data/files/950.pdf Accessed: 2010-09-10 